\title{
Climate change detection in penang island using deterministic interpolation methods
}

\author{
Chang Kok Yang ${ }^{1}$, Fam Pei Shan ${ }^{2}$, Tay Lea Tien ${ }^{3}$ \\ ${ }^{1,2}$ School of Mathematical Sciences, Universiti Sains Malaysia, Malaysia \\ ${ }^{3}$ School of Electrical and Electronic Engineering, Universiti Sains Malaysia, Malaysia
}

\begin{tabular}{l}
\hline Article Info \\
\hline Article history: \\
Received Nov 22, 2019 \\
Revised Jan 17, 2020 \\
Accepted Feb 4, 2020 \\
\hline
\end{tabular}

\section{Keywords:}

Climate change

Precipitation

Precipitation mapping

Spatial interpolation

\begin{abstract}
This paper presents detection of climate change in Penang Island by using precipitation data based on interpolation technique. Climate change brings about vast and everlasting effects on all living creatures on the Earth. These effects are especially detrimental towards heritage sites, landscapes and businesses based in Penang Island, Malaysia. This study focuses mainly on investigating the indication of climate change in Penang Island over the period of 2003-2018 by utilising sound application procedures of proven analysis methods. Two deterministic interpolation methods are used to produce new estimation points based on the precipitation data to enrich the monitoring network of rainfall stations in Penang Island. Monthly and monthly-average precipitation maps for Penang Island are produced by using inverse distance weighting interpolation method. Results reveal that seven out of twelve months of a year show increasing precipitation trends over the period of study and March is the only month that shows a decreasing trend in precipitation. Monthly-average precipitation in Penang Island also displays a gradual trend of precipitation increase over the period of study, further conforming the finding of monthly precipitation increase over the period of study. The finding of this study provides insight for local agriculturists and ministry to make better decision in response to climate change in Penang.
\end{abstract}

Copyright $\odot 2020$ Institute of Advanced Engineering and Science. All rights reserved.

\section{Corresponding Author:}

Fam Pei Shan,

School of Mathematical Sciences,

Universiti Sains Malaysia, 11800 USM Penang, Malaysia.

Email: fpeishan@usm.my

\section{INTRODUCTION}

Global warming has been an unquestioned occurring which happened in global scale. There is a significant warming trend throughout 20th century, which $70 \%$ of the global land area experienced a significant decrease in annual occurrence of cold nights and a significant increase in annual occurrence of warm nights [1]. The global warming trend is also projected to continue for another century [2]. Even in Malaysia which has a hot tropical weather with minimal variation in average temperature, the regional temperature is forecasted to rise by $1.5^{\circ} \mathrm{C}$ by year 2050 [3]. The increment might sound indifferent but the persistent heating occurring at the Northern Hemisphere and Southern Hemisphere leads to one critical global-scale aftermath, other than polar melting, that is climate change.

Climate is commonly described as the average conditions of the atmosphere surrounding the Earth, which comprise the conditions of temperature, wind and precipitation [4]. Climate change, on the other hand, is often depicted as the long-term, significant change in the average status of atmospheric condition or other climate elements, either in regional scale or in global scale. While historical evidences support the theory of climate change is part of natural phenomenon, which annual temperature of the Earth has fluctuated by several degree Celsius over the past million years, research scientists largely agree that the recent changes in climate occurring in the 20th century are inseparable from anthropological activities [5]. Climate change is the most 
widely concerned global issue and has vast and everlasting effects on all living creatures on the Earth, be it animal or botanical, such as threatened food security, habitat change and natural disasters [6]. Many of these occurrences are caused by precipitation changes, which arise as significant changes in the amount, intensity, frequency and type of precipitation, as well as the occurrence of precipitation anomalies and extremes.

Precipitation stands for all kinds of wet deposition of atmospheric moisture, such as hail, dew, rime, hoar frost, precipitation fog, rainfall and snowfall, which its intermittent occurrence hugely depends on temperature and weather conditions [7]. According to the National Aeronautics and Space Administration (NASA), precipitation is part of a process called the water (or hydrologic) cycle, a solar-powered, gigantic system which describes the continuous process of moisture exchange between the atmosphere, the oceans and the land. In the water cycle, water escapes from the oceans and the land to enter the atmosphere as vapour via the evapotranspiration process, which is composed of evaporation, transpiration and sublimation. The water vapour is then cooled by the cool air high up in the atmosphere and condenses into liquid form known as cloud droplets, which eventually fall back to the Earth's surface in the form of precipitation.

Global warming has a direct influence on precipitation, as global warming is expected to upscale the moisture exchange rate in the hydrological cycle and induces an intensification of precipitation extremes [8-9]. The Clausius-Clapeyron relation, a well-established physical law states that with every $1^{\circ} \mathrm{C}$ increase in temperature, the water-holding capacity of the atmosphere will increase by about 7\% [4]. This implies that warmer climate would generally lead to more intense precipitation events, even when the total annual precipitation decreases. The predictability of the occurrence and intensity of precipitation also deteriorate significantly as temperature increases [10].

In general, it is difficult to conclude that whether there has been any significant trend in global land precipitation throughout the twentieth century [11]. Studies justified that there is precipitation increase occurred both regionally and globally $[1-2,11-15]$. However, there are also studies showing contradictory results [4, 16-19]. Analysis of environmental events such as studying precipitation change is a challenging task, particularly because of the dynamic nature of the data [12].

The effects of climate change are also proven to be drastic, especially towards the agriculture in Malaysia. According to Department of Statistics Malaysia (available at https://www.dosm.gov.my), the gross output of agriculture sector in Malaysia recorded a whopping RM91.2 billion in 2017, which saw a $11.1 \%$ increase over that of year 2015. Agriculture in Malaysia contributed about 3.6\% of the Gross National Product (GNP) and more than one third of Malaysian population depends to the agriculture sector for their living [3]. An unfavourable climate, such as climate condition that is too wet or too dry, affects the cropping intensity as well as the workability of some key operations of agricultural activities such as seedbed preparation, planting and harvesting [20]. Climate change would cause large percentage changes in regional and local food supplies in low latitude regions [21]. Climate change is predicted to reduce major crop yields by $4.5 \%$ to $9 \%$ over the period of 2010-2039 and by a drastic 25\% in the long-run (2070-2099) projection [22-23]. With the growing evidence of the occurrence of precipitation extremes, understanding and prediction of precipitation distribution is important for water resources planning and management for a country that rely on agricultural needs, such as Malaysia [10,24]. While not limited to agriculture and crop yields alone, the effects of precipitation change are justified to be serious. Thus, in order to gain more understanding on the possible consequences of precipitation change on various aspects, it would be necessary and important to identify the indication of climate change over a region.

Penang Island embodies many objects, things and businesses that are crucial yet vulnerable to precipitation changes. These include the hilly terrain at the central area of Penang Island which is prone to occurrence of landslides under heavy rainfall, the durian plantation in Balik Pulau, the largest plantation of the Penang State which the production is highly influenced by climate condition and George Town, the precious, centuries old UNESCO World Heritage Site of Malaysia which is extremely delicate against erosion. All these aspects produce the importance of investigating and understanding the indication of climate change over the region. This paper presents detection of climate change in Penang Island by using precipitation data based on interpolation technique. Two deterministic spatial interpolation methods, i.e. inverse distance weighting (IDW) and old number ratio with inverse distance weighting (ONRIDW) are deployed to produce monthly and monthly-average precipitation maps of Penang Island, Malaysia over the 16 years period of 2003-2018.

\section{RESEARCH METHOD}

Rain gauges are installed at six different rainfall stations in Penang Island to collect precipitation data over the region. Inverse distance weighting (IDW) and old number ratio with inverse distance weighting (ONRIDW) methods are used to produce new estimation points to enrich and enlarge the coverage of the network of rainfall stations in Penang Island in attempt to increase the capability of the network in capturing and representing the actual distribution of precipitation over the region. The number of new estimation points 
is kept streamline to avoid redundancy and to minimize the degree of error yielded. The geographic location coordinates of the resulting network of rainfall stations are recorded in Table 1. Figure 1 shows the respective locations of the stations in Penang Island:

Table 1. Geographic location coordinates of the rainfall stations in penang island

\begin{tabular}{cccc}
\hline Rainfall Station & Station Number & Longitude (DD) & Latitude (DD) \\
\hline Tali Air Besar Sg. Pinang & 5302001 & 100.212500 & 5.391667 \\
Pintu Air Bagan & 5302002 & 100.200000 & 5.354167 \\
Kolam Takungan Air Itam & 5302003 & 100.265278 & 5.395833 \\
Bukit Bendera & 5402001 & 100.270833 & 5.423611 \\
Kolam Bersih & 5402002 & 100.286111 & 5.440278 \\
Lorong Batu Lanchang & 5403001 & 100.285556 & 5.502222 \\
New Point A & - & 100.213000 & 5.433000 \\
New Point B & - & 100.240000 & 5.394000 \\
New Point C & - & 100.260000 & 5.361000 \\
\hline
\end{tabular}

\section{Penang Rainfall Stations}

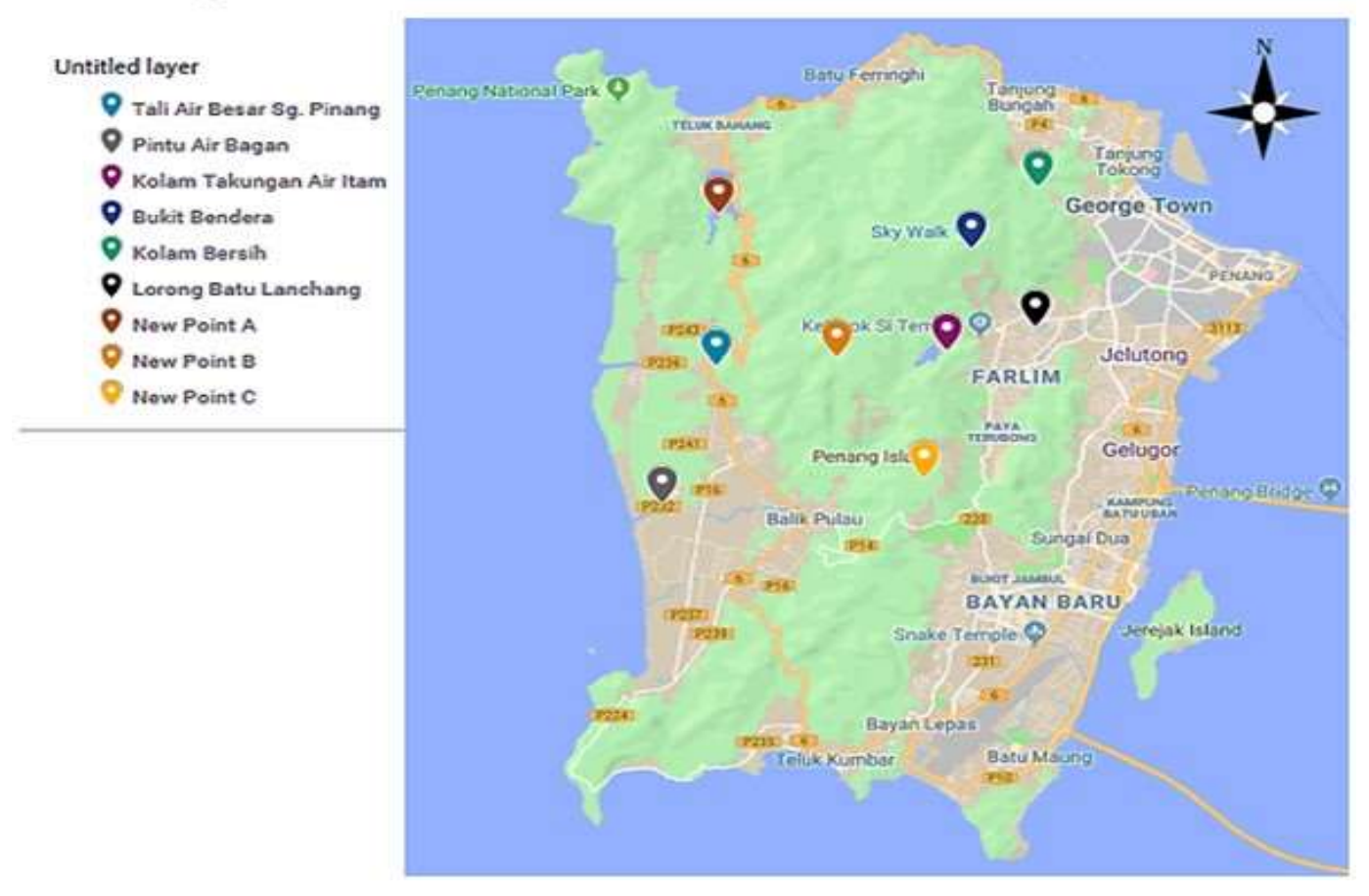

Figure 1. Location of the rainfall stations in penang island

With the obtained precipitation data, it would be feasible to estimate precipitation values at new estimation points by using a linear combination of the observed precipitation values and the respective weights calculated with selected interpolation methods [25]. The method of estimation is expressed as:

$$
\hat{R}_{k}=\sum_{i=1}^{N} W_{i} R_{i}
$$

where

- $\hat{R}_{k}$ is the estimated precipitation value at new estimation point $k$;

- $R_{i}$ is the recorded precipitation value at station $i$

- $\quad N$ is the total number of surrounding stations, which $i=1,2,3, \ldots, N$;

- $W_{i}$ is the calculated weight for station $i$, with the condition of $\sum_{i=1}^{N} W_{i}=1$. 
There are numerous methods for calculating the corresponding weight, $W_{i}$ associated with station $i$. However, two deterministic interpolation methods, namely IDW and ONRIDW, are the methods of choice in this study due to the verified high performance and precision of the methods in estimating precipitation data in Penang island [26]. IDW is one of the most widely applied interpolation methods for various functions, such as data estimation and spatial modelling [27]. IDW method estimates the values of an attribute of interest at unsampled points using a linear combination of values at sampled points weighted by an inverse function of the distance between the point of interest and the sampled points. The general expression of IDW could be defined as:

$$
W_{i}=\frac{d_{i k}^{-p}}{\sum_{i=1}^{N} d_{i k}^{-p}}
$$

where

- $d_{i k}$ is the distance between estimation point $k$ and station $i$

$-\quad p$ is the power parameter.

The weight, $W_{i}$ calculated by IDW method diminishes as the distance between estimation point $k$ and station $i$ increases, and the degree of decrement escalates as the value of power parameter increases [28]. The optimal parameter for IDW have a radius of influence up to $15-60 \mathrm{~km}$, and the optimal power parameter value, $p$ varies between 1 and 5 [29]. The commonly used value for $p$ is 2 [30].

ONRIDW is essentially a modification based on the older, simple and poor performing old number ratio method (ONRM) and modified normal ratio based on square root distance (MNRT) [31]. The formula of ONRIDW could be expressed as:

$$
W_{i}=\frac{\frac{\mu_{k}}{\mu_{i}} d_{i k}^{-p}}{\sum_{i=1}^{N} \frac{\mu_{k}}{\mu_{i}} d_{i k}^{-p}}
$$

Where

- $\mu_{k}$ is the average precipitation of estimation point $k$ within a selected time frame;

- $\mu_{i}$ is the average precipitation of station $i$ within a selected time frame;

- $d_{i k}$ is the distance between estimation point $k$ and station $i$;

- $p$ is the power parameter.

The estimation of precipitation values of the new estimation points would then be commenced with replacing the values of $W_{i}$ obtained by (2) and (3) into (1).

\section{RESULTS AND ANALYSIS}

Following the visual inspection and analysis, the monthly precipitation in Penang Island shows inconsistency in the behaviour and trend of changes for each of the respective months over the period of 20032018. However, majority of the months suggest precipitation increase in Penang Island with the colour hue of the precipitation maps gradually turning cooler over the period of 2003-2018, despite occasional occurrence of precipitations that are drier or wetter than usual. The examples of precipitation mappings produced are as shown in Figures 2 and 3. Figure 2 shows the precipitation maps for the month May from 2003 to 2018, which the colour hue of the maps turns cooler over time, justifying the increase in monthly precipitation in Penang Island at the month of May. Figure 3, on the other hand, shows that the monthly precipitation for the month of March in Penang Island shows a trend of decrease over the period of 2003-2018, which the colour hue of the maps turns warm over time. Figure 4 shows the standardized classification used on the precipitation maps.

Table 2 summarizes the finding on change in monthly precipitation in Penang Island over the period of 2003-2018. Seven out of the twelve months of a year, namely January, April, May, July, September, November and December display humidified precipitation over the period of study. Despite that, May, September, November and December show significant indications of precipitation increase while the other months show less obvious but gradual trend of precipitation increase. On the other hand, February, June, August and October do not show any significant sign of change in precipitation over the study period. Moreover, over the period of study, March is the only month that shows decreasing trend in precipitation. Hence, it is more prominent that the monthly precipitation in Penang Island has an increasing trend between 2003 and 2018. 

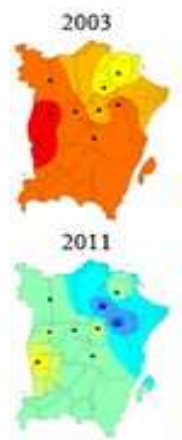

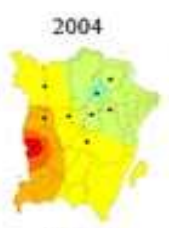

2012

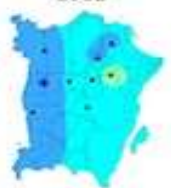

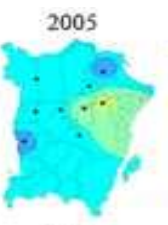

2013

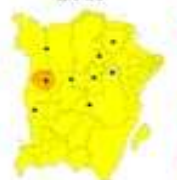

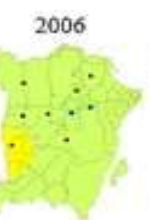

2014

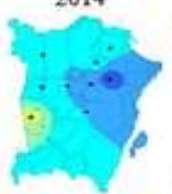

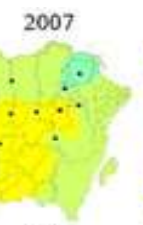

2015

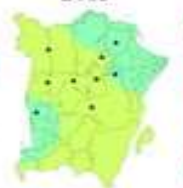

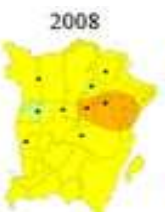

2016

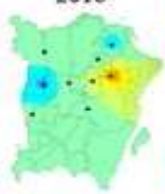

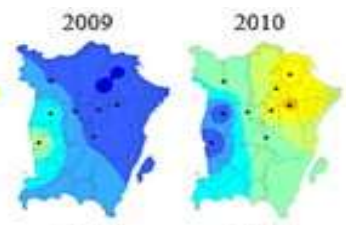

2017

2018

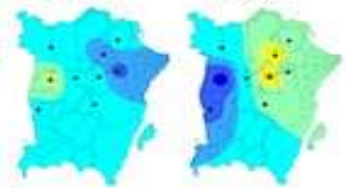

Figure 2. Precipitation maps of May in Penang Island for 2003-2018 with increasing trend in precipitation

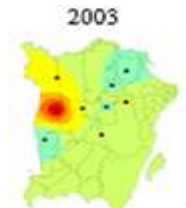

2011

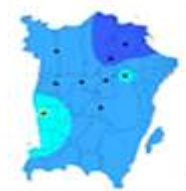

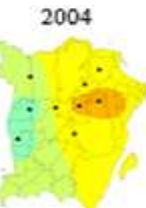

2012

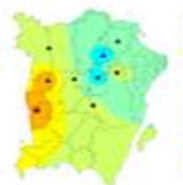

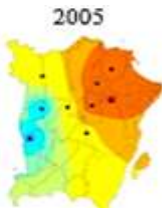

2013

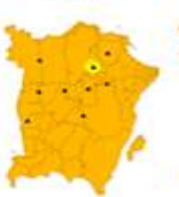

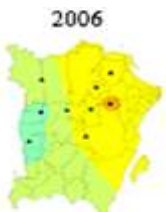

2014

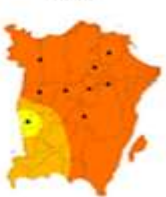

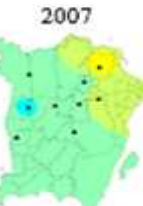

2015

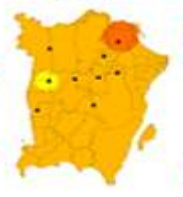

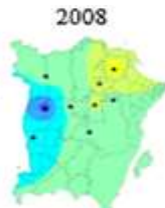

2016

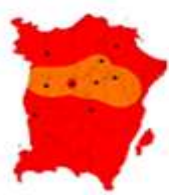

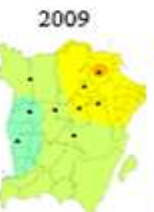

2017

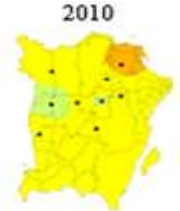

2018

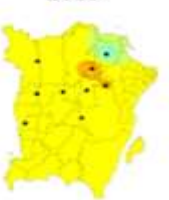

Figure 3. Precipitation maps of March in Penang Island for 2003-2018 with decreasing trend in precipitation

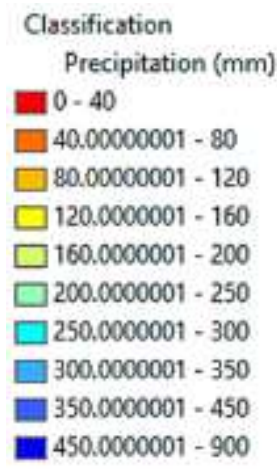

Figure 4. The classification of the precipitation maps in Penang Island
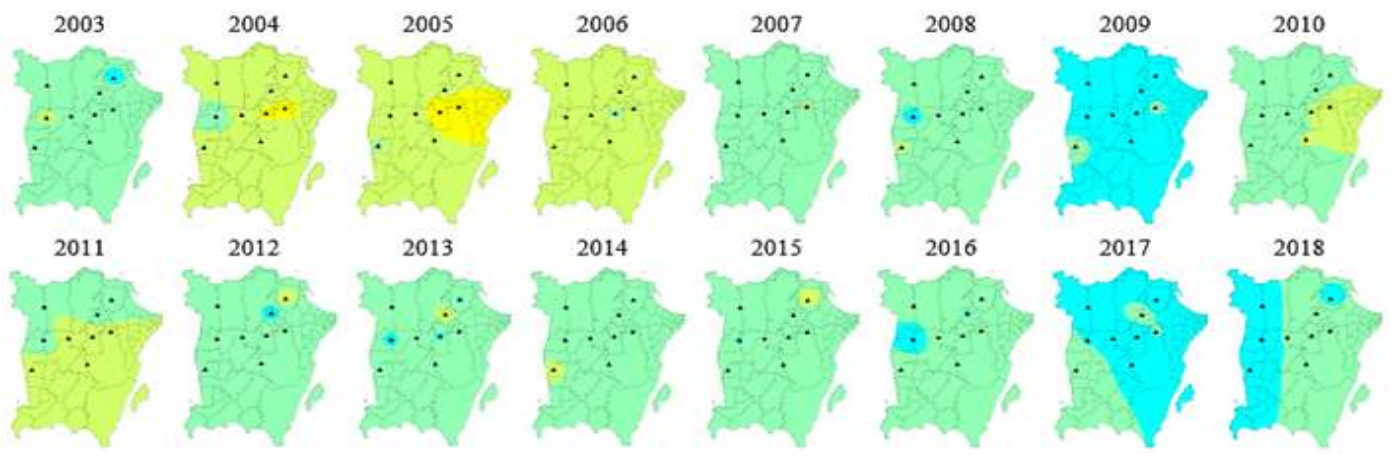

Figure 5. Monthly-average precipitation maps in Penang Island for 2003-2018 
Table 2. Summary of the findings on monthly precipitation in Penang Island for 2003-2018

\begin{tabular}{cccc}
\hline Significant & Gradual Precipitation & No Precipitation & Precipitation \\
Precipitation Increase & Increase & Change & Decrease \\
\hline May & January & February & March \\
September & April & June & \\
November & July & August & \\
\hline
\end{tabular}

The finding on the monthly-average precipitation further solidify the inference on the monthly precipitation in Penang Island. As shown in Figure 5, the precipitation maps of monthly-average precipitation in Penang Island show gradual cooling in the colour hue of the mappings over the study period, suggesting a gradual increasing trend in the monthly-average precipitation in Penang Island. It was justified that Penang showed no linear trend in precipitation over the period of 1951-1991 [32,33]. Hence, it is deemed that the occurrence of precipitation increase in Penang Island has just began since $21^{\text {st }}$ century.

The indication of climate change in terms of precipitation change have not been justified in Penang Island in previous studies. This might be particularly due to the dynamic nature of the precipitation data in Penang Island, as the precipitation pattern and distribution in Penang Island is prominently affected by the seasonal monsoon system experienced regionally. Analysing the monthly precipitation data in Penang Island in year-by-year manner successfully captures the pattern of change in monthly precipitation in Penang Island without overlooking the dynamic and seasonal nature in the data. Presentation of the result of this study in the form of precipitation mappings allows local agriculturists and ministry in Penang Island to understand the change in precipitation distribution and intensity over the region, even without expertise in data analysis. In short, this study proposes sound application procedure of conventional and proven methods of analysis, which data could be transformed into meaningful presentation that is easy to interpret and understand.

\section{CONCLUSION}

This paper presents detection of climate change in Penang Island by using precipitation data based on interpolation technique. Two deterministic interpolation methods, IDW with value of power parameter, $p=1$ and ONRIDW with $p=2$ are used to create three new estimation points to enrich the monitoring network of rainfall stations in Penang Island before commencing the generation of precipitation maps over the region. The precipitation maps for the monthly and monthly-average precipitation in Penang Island are produced over the period of 2003-2018. Analysis reveals that there have been trends of increase in monthly precipitation for seven out of the twelve months of a year, namely January, April, May, July, September, November and December. Despite that, May, September, November and December show significant indications of precipitation increase while the three other months show less obvious but gradual trend of precipitation increase. March is the only month that shows decreasing trend in precipitation, whereas February, June, August and October display no significant sign of precipitation change.

Monthly-average precipitation, furthermore, displays a gradual trend of precipitation increase, which further conforms the finding of monthly precipitation increase over the period of study. The result of this study is also supporting the findings of several previous studies. Also, it is deemed that the occurrence of precipitation increase in Penang Island has just began since 21st century. Local agriculturists as well as local ministry could incorporate the finding of this study into future decision making to make better preparation and response to the change in Penang climate. Sound application procedure of conventional and proven methods of analysis is also proposed in this study, which data could be transformed into meaningful presentation that is easy to interpret and understand.

It is advisable for further studies to take the parameters not covered in this study, such as elevation, precipitation intensity and precipitation duration, into the scope of study to ensure a more comprehensive and precise inference on the precipitation distribution and climate change over the area of study. Following this study, it is recommendable for JPS to restore the Bayan Lepas Rainfall Station, with station number 5202021, located at the southern area of the Penang Island, into operation to complement the current monitoring networks of rainfall stations in Penang Island. With this, researchers would be able to produce more comprehensive, detailed and precise findings for future meteorological researches over the region.

\section{ACKNOWLEDGEMENTS}

This research work is supported by RUI Grant (1001/PMATHS/8011093). 


\section{REFERENCES}

[1] L. V. Alexander, et al., "Global observed changes in daily climate extremes of temperature and precipitation," Journal of Geophysical Research, vol. 111, 2006.

[2] K. R. Kumar, et al., "High-resolution climate change scenarios for India for the 21st century," Current Science, vol. 90, no. 3, pp. 334-345, 2006.

[3] H. A. Rahman, "Global climate change and its effects on human habitat and environment in Malaysia," Malaysian Journal of Environmental Management, vol. 10, no. 2, pp. 17-32, 2009.

[4] S. Solomon, et al., "Climate change 2007: The physical science basis," Working Group I Contribution to the Fourth Assessment Report of the Intergovernmental Panel on Climate Change, vol. 4, 2007.

[5] Y. Y. Loo, et al., "Effect of climate change on seasonal monsoon in Asia and its impact on the variability of monsoon rainfall in Southeast Asia," Geoscience Frontiers, vol. 6, no. 6, pp. 817-823, 2015.

[6] D. H. Kazmi, et al., "A statistical downscaling model for summer rainfall over Pakistan," Climate Dynamics, vol. 47, no. 7-8 pp. 2653-2666, 2016.

[7] WMO, "Guide to Climatological Practices." World Meteorological Organisation (WMO), 2011.

[8] P. A. O'Gorman, et al., "The physical basis for increases in precipitation extremes in simulations of 21st-century climate change," Proceedings of the National Academy of Sciences, vol. 106, no. 35, pp. 14773-14777, 2009.

[9] K. E. Trenberth, "Changes in precipitation with climate change," Climate Research, vol. 47, no. 1-2, pp. 123-138, 2011.

[10] N. Z. M. Safar, et al., "Rain prediction using fuzzy rule based system in North-West Malaysia," Indonesian Journal of Electrical Engineering and Computer Science, vol. 14, no. 3, pp. 1572-1581, 2019.

[11] M. New, et al., "Precipitation measurements and trends in the twentieth century," International Journal of Climatology: A Journal of the Royal Meteorological Society, vol. 21, no. 15, pp. 1889-1922, 2011.

[12] M. H. A. Abdullah, et al., "Evolving spiking neural networks methods for classification problem: A case study in flood events risk assessment," Indonesian Journal of Electrical Engineering and Computer Science, vol. 16, no. 1, pp. 222-229, 2019.

[13] G. A. Meehl, et al., "Global climate projections," Climate Change 2007: The Physical Science Basis. Contribution of Working Group I to the Fourth Assessment Report of the Intergovernmental Panel on Climate Change, Cambridge University Press, Cambridge, (2007)

[14] C. Siwar, et al., "A review of the linkages between climate change, agricultural sustainability and poverty in Malaysia," International Review of Business Research Papers, vol. 5, no. 6, pp. 309-321, 2009.

[15] B. Wang, et al., "Recent change of the global monsoon precipitation (1979-2008)," Climate Dynamics, vol. 39, no. 5, pp. 1123-1135, 2011.

[16] M. J. Manton, et al., "Trends in extreme daily rainfall and temperature in southeast asia and the south pacific: 19611998," International Journal of Climatology, vol. 21, no. 3, pp. 269-24, 2001.

[17] K. E. Trenberth, et al., "Observations: Surface and atmospheric climate change," Intergovernmental Panel on Climate Change 4th assessment report, pp. 235-336, 2007.

[18] N. Endo, et al., "Trends in precipitation extremes over southeast asia," Sola, vol. 5, pp. 168-171, 2009.

[19] D. Ganguly, et al., "Fast and slow responses of the South Asian monsoon system to anthropogenic aerosols," Geophysical Research Letters, vol. 39, no. 18, pp. 1-5, 2012.

[20] T. Iizumi, et al., "How do weather and climate influence cropping area and intensity?," Global Food Security, vol. 4, pp. 46-50, 2015.

[21] M. A. Richard, et al., "Effects of global climate change on agriculture: An interpretative review," Climate Research, vol. 11, pp. 19-30, 1998.

[22] R. Guiteras, "The impact of climate change on indian agriculture," University of Maryland, 2009.

[23] J. Wang, et al., "The impact of climate change on China's agriculture," Agricultural Economics, vol. 40, pp. 323-337, 2009.

[24] S.M. Shaharudin, et al., "Modified singular spectrum analysis in identifying rainfall trend over peninsular Malaysia," Indonesian Journal of Electrical Engineering and Computer Science, vol. 15, no. 1, pp. 283-293, 2019.

[25] D. Shepard, "A two-dimensional interpolation function for irregularly-spaced data," Proceedings of the $196823 \mathrm{rd}$ ACM national conference, ACM, pp. 517-524, 1968.

[26] H. Y. Lim, et al., "Estimation of precipitation data by using deterministic interpolation methods: A case study in penang island," Proceedinds of Internatinal Conference on Mathematical Sciences and Technology, 2018.

[27] P. d. A. Borges, et al., "Comparison of spatial interpolation methods for the estimation of precipitation distribution in Distrito Federal, Brazil," Theoretical and Applied Climatology, vol. 123, pp. 335-348, 2015.

[28] M. Keblouti, et al., "Spatial interpolation of annual precipitation in annaba-algeria - comparison and evaluation of methods," Energy Procedia, vol. 18, pp. 468-475, 2012.

[29] M. J. Noori, et al., "Spatial Estimation of Rainfall Distribution and Its Classification in Duhok Governorate Using GIS," Journal of Water Resource and Protection, vol. 6, pp. 75-82, 2014.

[30] R. S. Teegavarapu, et al., "Improved weighting methods, deterministic and stochastic data-driven models for estimation of missing precipitation records," Journal of Hydrology, vol. 312, no. 1-4, pp.191-206, 2005.

[31] J. Suhaila, et al., "Revised spatial weighting methods for estimation of missing rainfall data," Asia-Pacific Journal of Atmospheric Sciences, vol. 44, no. 2, pp.93-104, 2008.

[32] B. K. Cheang, "Interannual variability of monsoons in Malaysia and its relationship with ENSO," Proceedings of the Indian Academy of Sciences - Earth and Planetary Sciences, vol. 102, pp. 219-239, 1993.

[33] C. Siwar, et al., "A review of the linkages between climate change, agricultural sustainability and poverty in Malaysia," International Review of Business Research Papers, vol. 5, no. 6, pp. 309-321, 2009. 


\section{BIOGRAPHIES OF AUTHORS}

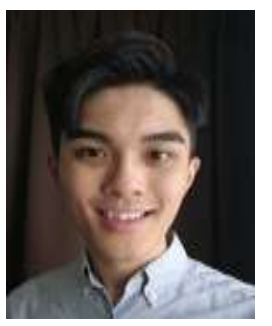

Chang Kok Yang, fresh graduate with Bachelor of Applied Science (Applied Statistics) from the School of Mathematical Sciences, Universiti Sains Malaysia. Worked closely with and under supervision of Dr. Fam Pei Shan, senior lecturer of the School of Mathematical Sciences, Universiti Sains Malaysia to conduct meteorology and mathematical related study while pursuing tertiary education in Universiti Sains Malaysia.

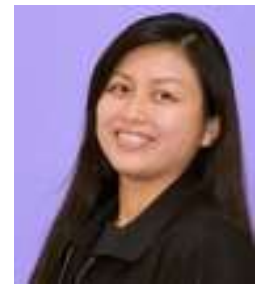

Fam Pei Shan received her Ph. D. degree in statistics from University of Malaya in year 2011. She is currently senior lecturer in school of Mathematical Sciences, Univerisiti Sains Malaysia. Her research interests include categorical data analysis, and logistics regression analysis. She is also active in landslide prediction study.

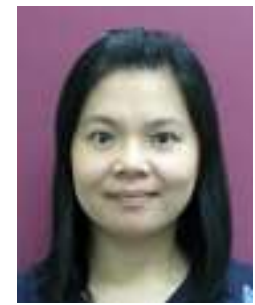

Tay Lea Tien is senior lecturer at School of Electrical and Electronic Engineering, Universiti Sains Malaysia. She obtained Bachelor of Electrical Engineering Degree from Uniersity of Malaya, Master of Eng. Sc. and PhD in Engineering from Multimedia Universtity, Malaysia. She has been actively carried out research work in landslide hazard mapping for the past 8 years. Her research areas include remote sensing image processing, landslide hazard mapping and load flow analysis. 